\title{
CLOSE-RANGE SENSING TECHNIQUES IN ALPINE TERRAIN
}

\author{
M. Rutzinger ${ }^{\mathrm{a}, \mathrm{b}}$, B. Höfle ${ }^{\mathrm{c}, \mathrm{d}}$, R. Lindenbergh ${ }^{\mathrm{e}}$, S. Oude Elberink ${ }^{\mathrm{f}}$, F. Pirotti ${ }^{\mathrm{g}}$, R. Sailer ${ }^{\mathrm{a}}$, M. Scaioni ${ }^{\text {h,i }}$, J. Stötter ${ }^{\mathrm{a}}$, D. Wujanz $^{\mathrm{j}}$ \\ ${ }^{\text {a } I n s t i t u t e ~ o f ~ G e o g r a p h y, ~ U n i v e r s i t y ~ o f ~ I n n s b r u c k, ~ A u s t r i a ~-~ m a r t i n . r u t z i n g e r, ~ r u d o l f . s a i l e r, ~ h a n s . s t o e t t e r @ u i b k . a c . a t ~}$ \\ ${ }^{\mathrm{b}}$ Institute for Interdisciplinary Mountain Research, Austrian Academy of Sciences, Austria - martin.rutzinger@oeaw.ac.at \\ ${ }^{c}$ GIScience, Institute of Geography, Heidelberg University, Germany - hoefle@uni-heidelberg.de \\ ${ }^{\mathrm{d}}$ Heidelberg Center for the Environment (HCE), Heidelberg University, Germany \\ ${ }^{\mathrm{e}}$ Dept. of Geoscience \& Remote Sensing, Delft University of Technology, The Netherlands - \\ r.c.lindenbergh@tudelft.nl \\ ${ }^{\mathrm{f}}$ ITC - Faculty of Geo-Information Sciences and Earth Observation, University of Twente, The Netherlands - \\ s.j.oudeelberink@utwente.nl \\ ${ }^{\mathrm{g}}$ Interdepartmental Research Center of Geomatics (CIRGEO), University of Padova - francesco.pirotti@unipd.it \\ ${ }^{\mathrm{h}}$ Department of Architecture, Build Environment and Construction Engineering, Politecnico di Milano, Italy - \\ marco.scaioni@polimi.it \\ ${ }^{i}$ College of Surveying and Geo-Informatics, Tongji University, Shanghai, P.R. China - marco@tongji.edu.cn \\ ${ }^{\mathrm{j}}$ Institute of Geodesy and Geoinformation Science, Technische Universität Berlin, Germany - daniel.wujanz@tu-berlin.de
}

\section{Commission VI, WG VI/5}

KEY WORDS: knowledge transfer, PhD training, summer school, natural hazards, vegetation mapping, glaciology, bathymetry, terrestrial laser scanning, close-range photogrammetry, thermography, education

\begin{abstract}
:
Early career researchers such as $\mathrm{PhD}$ students are a main driving force of scientific research and are for a large part responsible for research innovation. They work on specialized topics within focused research groups that have a limited number of members, but might also have limited capacity in terms of lab equipment. This poses a serious challenge for educating such students as it is difficult to group a sufficient number of them to enable efficient knowledge transfer. To overcome this problem, the Innsbruck Summer School of Alpine Research 2015 on close-range sensing techniques in Alpine terrain was organized in Obergurgl, Austria, by an international team from several universities and research centres. Of the applicants a group of 40 early career researchers were selected with interest in about ten types of specialized surveying tools, i.e. laser scanners, a remotely piloted aircraft system, a thermal camera, a backpack mobile mapping system and different grade photogrammetric equipment. During the one-week summer school, students were grouped according to their personal preference to work with one such type of equipment under guidance of an expert lecturer. All students were required to capture and process field data on a mountain-related theme like landslides or rock glaciers. The work on the assignments lasted the whole week but was interspersed with lectures on selected topics by invited experts. The final task of the summer school participants was to present and defend their results to their peers, lecturers and other colleagues in a symposium-like setting. Here we present the framework and content of this summer school which brought together scientists from close-range sensing and environmental and geosciences.
\end{abstract}

\section{INTRODUCTION}

Environmental monitoring and mapping is a major task but also a challenge for the quantification of processes, especially in mountainous areas. The steep terrain and highly changeable surfaces as a result, for instance, of frequently recurrent natural processes require a special design of measurement and mapping methods. Close-range sensing techniques are by definition well suited to be used in the field and therefore can be flexibly applied for mapping tasks. However, data acquisition and data processing may need a specific set-up depending on the thematic research question in monitoring and mapping to which it will be applied. The operator has to be aware of special requirements of a certain application as well as of specific sensor properties and error budgets. Thus there is a fundamental gap to bridge between knowledge on sensing technology and requirements defined by the target application in environmental and geoscience.

The Innsbruck Summer School of Alpine Research 2015 was jointly organized by the Institute of Geography (University of Innsbruck) and the International Society for Photogrammetry and Remote Sensing - ISPRS (Working Groups III/2: 3D Point Cloud Processing and $\mathrm{V} / 3$ : Terrestrial 3D Imaging and Sensors). The objective of the summer school was to design and implement an interdisciplinary concept aimed at bringing together scientists, PostDocs and $\mathrm{PhD}$ students from both technical sciences and environmental and geosciences working in the field of mountain research (Tab. 1). After registration opened for the summer school in October 2014, 120 people registered sending their $\mathrm{CV}$ and a motivation letter. Forty participants were selected by the organizing committee, which adopted a predefined set of selection criteria and weights (Fig. 1 and 2).

The interdisciplinary concept was carried out on all levels throughout the summer school, from assembling the organizing committee, inviting keynote speakers and lecturers, selecting participants to defining assignments for students' groups. The technical background included research fields from photogrammetry, laser scanning, geomatics and geoinformation, geodesy, and remote sensing. The thematic research background included geography, ecology, forestry, mountain research, natural hazards and risk research, climatology and climate 
change, glaciology, geomorphology; just to name the most important ones.

\begin{tabular}{|l|c|c|c|}
\hline & $\begin{array}{l}\text { Technical } \\
\text { science } \\
\text { background }\end{array}$ & $\begin{array}{l}\text { Environmental } \\
\text { and geo- } \\
\text { science } \\
\text { background }\end{array}$ & Nationalities \\
\hline $\begin{array}{l}\text { Organizing } \\
\text { Committee }\end{array}$ & 4 & 4 & 5 \\
\hline $\begin{array}{l}\text { Keynotes \& } \\
\text { Lecturers }\end{array}$ & 4 & 4 & 4 \\
\hline Participants & 20 & 20 & 15 \\
\hline
\end{tabular}

Table 1. Composition of organizing committee, keynote speakers, lecturers, and participants

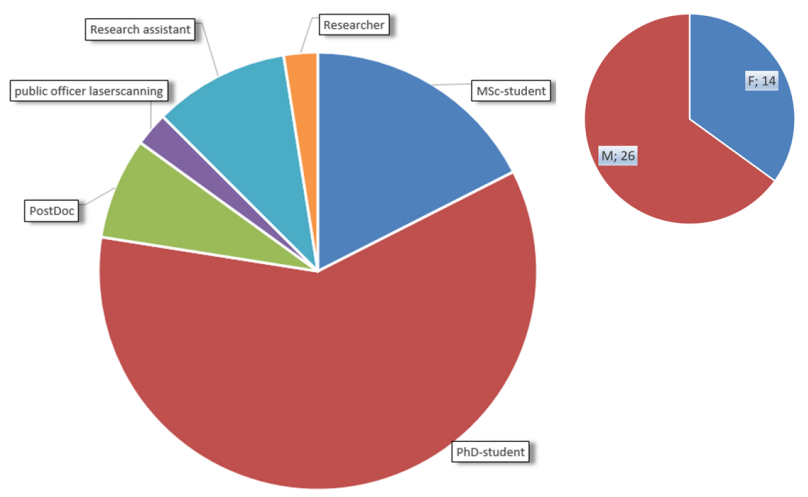

Figure 1. Breakdown of participants' profile (left) and gender (right)

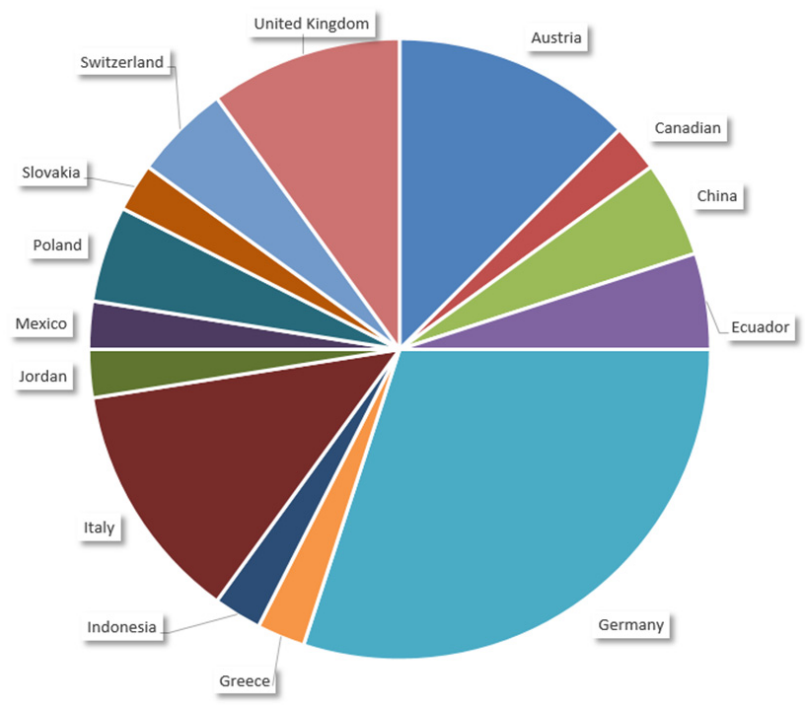

Figure 2. Breakdown of participants' country of origin

The University Centre at Obergurgl (Tyrol, Austria) was chosen as the venue. The centre served as a field lab offering various opportunities to investigate environmental changes driven by climate, hydrology, vegetation, cryosphere, geomorphology and geological processes.

\section{DIDACTIC CONCEPT}

The Innsbruck Summer School of Alpine Research 2015 was designed as an interdisciplinary learning and knowledge exchange event, with three main pillars (Fig. 3). The first pillar were lectures by invited experts, experienced practitioners and academics, framing mainly the theoretical background of sensors and platforms, processing methods and scientific applications with a focus on topics related to environmental and geoscience i.e. mountain research. Academic lectures included keynotes from scientists giving broad overviews of their fields. The second pillar were group assignments, hands-on projects conducted by groups of about five participants. All groups were supervised by an experienced researcher. The assignment topics again reflected a combination of sensor, data processing and thematic research. The participants had to compile a project concept first, pre-test sensor and data acquisition, capture data in the field, process the data sets and perform analyses relevant to their assigned theme. Finally, as a third pillar, every group gave an oral presentation to all participants defending their project approach. Equally important, the summer school also provided ample time and space for social and networking activities. This included an ice breaker event, a photo competition and a joint hike one afternoon.

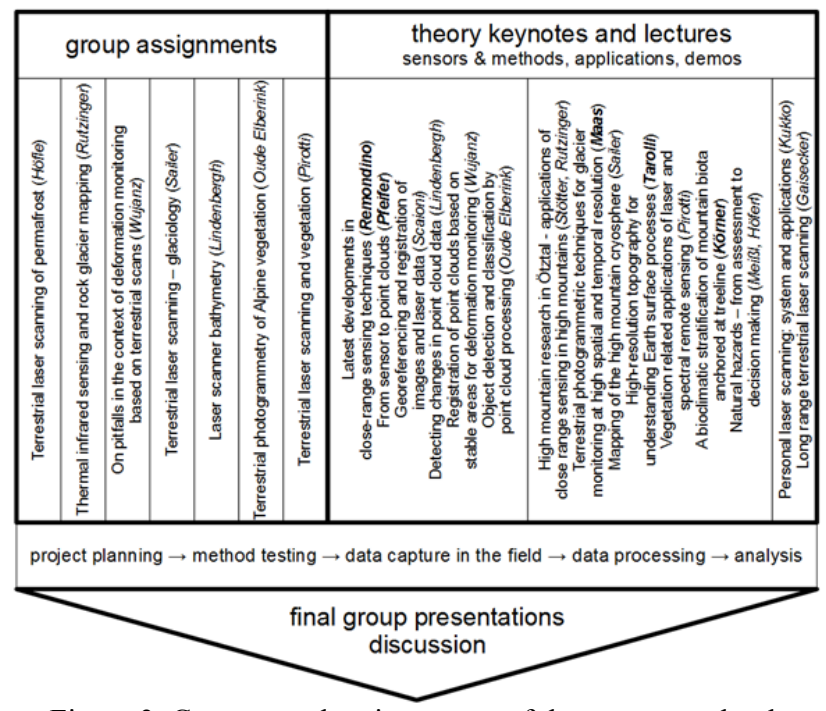

Figure 3. Concept and main content of the summer school. Names of keynote speakers in bold

All material, including presentations, data sets, exercises, literature and links were made available using the e-learning platform OLAT (Online Learning and Training) hosted by the University of Innsbruck. In addition to data exchange, the platform included a discussion forum where participants, lecturers and group supervisors could communicate before, during and after the summer school.

\section{CONTENTS}

The summer school taught close-range sensing techniques of selected sensors and platforms applied to scientific tasks relevant in mountain research on topics in environmental and geoscience. The focus of sensor types was on terrestrial laser scanning (TLS) including geometric, radiometric and multispectral aspects, registration and georeferencing of point clouds. Furthermore, new laser platforms, such as a backpack laser scanning (BPLS), were tested. Optical sensors have been used for processing oblique images from the ground and images acquired by remotely piloted aircraft systems (RPAS) with a focus on classical photogrammetry, structure from motion (SFM), dense matching and thermal infrared sensing (TIS). These sensors were used for mapping and change detection tasks applied in researching vegetation, mass movements, glaciology and permafrost (i.e. rock glacier), bathymetry and braided river systems. 
The keynotes and lectures covered (i) sensor-platform-specific topics and methods of data processing, (ii) bridging methods and themed research, and (iii) specific themes (Fig. 3, right column). Two demos underlined data collection in the field and data processing possibilities. These keynotes and lectures were the theoretical basis for the group assignments, which are introduced in the following subsections, where they are described in detail by the objectives, study site and sensor used by each group, with added references to related lectures on the thematic background.

\subsection{Vegetation mapping}

3.1.1 Terrestrial laser scanning: This team was tasked with comparing two terrestrial laser systems for vegetation mapping. Participants analysed datasets from two sensors, one acquired during a demonstration of the BPLS survey by Kukko A. (Kukko et al., 2012) and one from a static TLS. The latter was a Leica P20 capturing about 20 million points from three positions with an average point spacing of $0.02 \mathrm{~m}$ (Fig. 4). During the assignments participants learned how to plan a TLS survey, register point clouds, calculate differences in accuracy of two laser scanner surveys, display data and visually analyse scalar values, test methods for classifying point clouds into low vegetation (grass and bushes), and high vegetation (trees), apply a confusion matrix and calculate accuracy indices to assess classification results (Fig. 5).

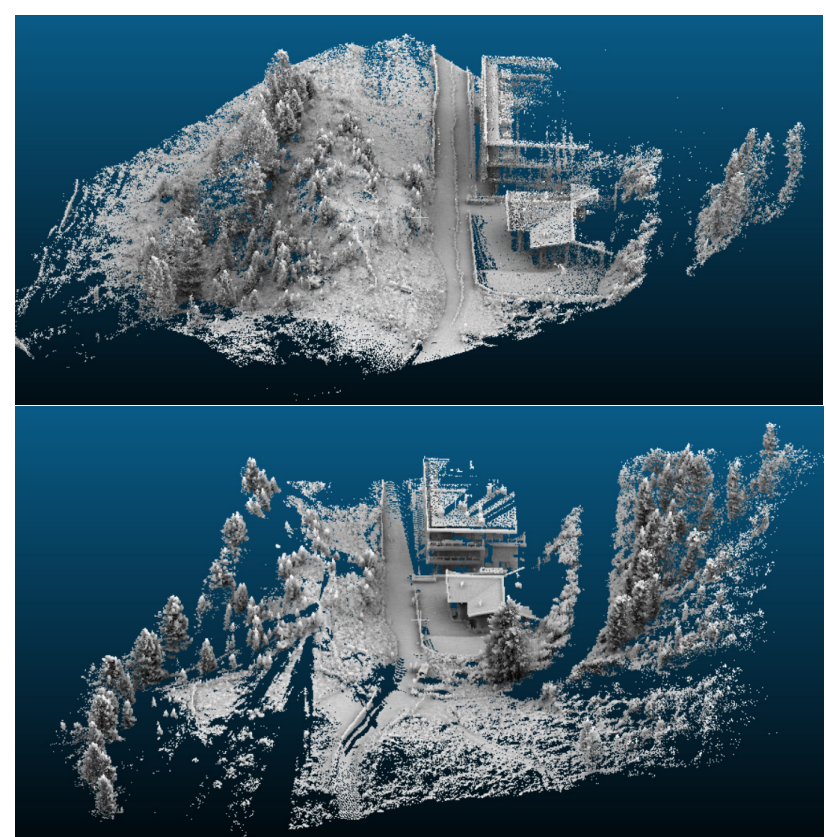

Figure 4. Visual comparison of point clouds from backpack LiDAR (upper) and terrestrial laser scanning (lower)
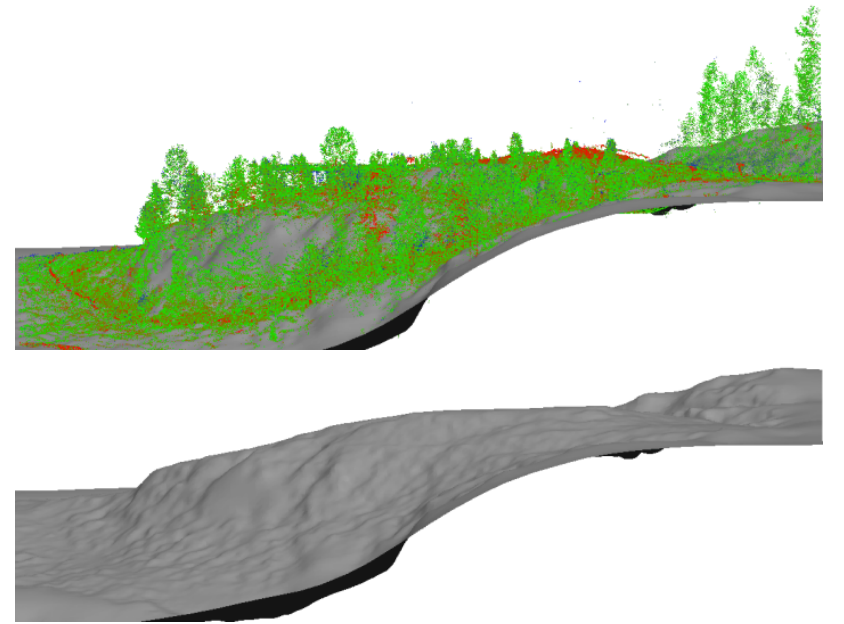

Figure 5. Classified vegetation in terrestrial laser scanning point cloud (upper) and filtered digital terrain model (lower)

3.1.2 Close-range photogrammetry: This group compared five different cameras applying close-range photogrammetry techniques (e.g. Luhmann et al., 2013), i.e., 3D point cloud generation from dense matching (e.g. Remondino et al., 2014). The cameras tested were: Canon5D, GoPro Hero3+, LG D331, Konica, Nikon D3000. All cameras were used to take photographs from 15 predefined positions. An $1 \mathrm{~m}$ scale bar was placed in the scene for scaling (Fig. 6). Several approaches for $3 \mathrm{D}$ point cloud generation were tested by using five different software packages, i.e. AgiSoft PhotoScan, VisualSFM, SURE, MicMac and CloudCompare. Segmentation and classification techniques were applied to distinguish rock surfaces from vegetation structures, e.g. AgiSoft PhotoScan segmentation and CANUPO, see Brodu \& Lague 2012. In Figure 7 the rock surface was identified by applying a ground detection algorithm using the relative height above the lowest points as a constraint in a connected component algorithm, as described by Oude Elberink and Kemboi (2014).

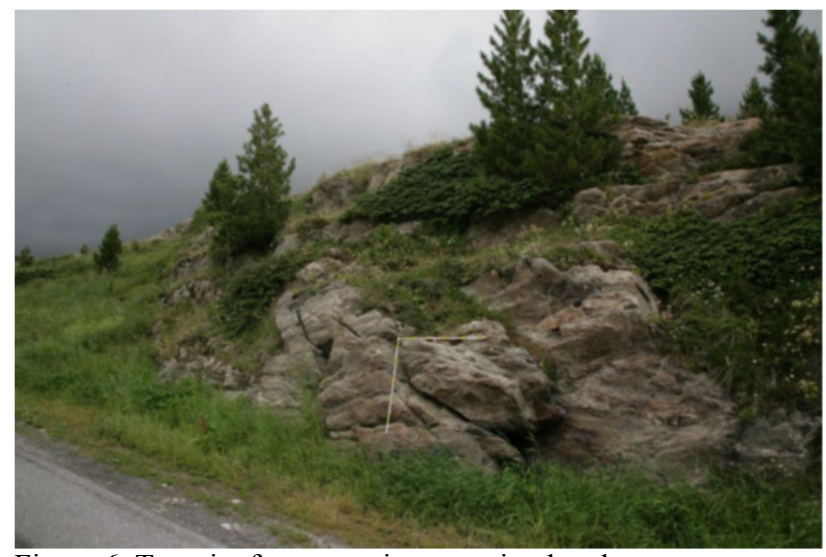

Figure 6 . Test site for vegetation mapping by close-range photogrammetry 

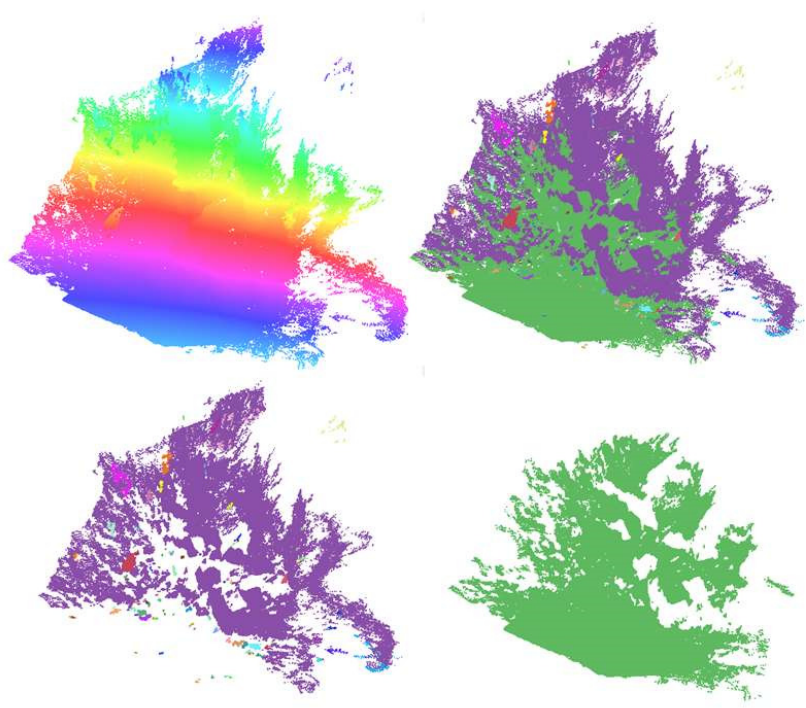

Figure 7. Point cloud generated Agisoft (upper left), segmentation result (upper right), divided into above ground components (bottom left) and the rock surface (bottom right)

3.1.3 Related vegetation and forestry lectures: A general lecture about specific vegetation properties in mountain regions, esp. treeline, location properties and climate conditions was given by Körner C. entitled $A$ bioclimatic stratification of mountain biota anchored at treeline (see e.g. Körner, 2012). The keynote by Remondino, F. Latest developments in closerange techniques gave a comprehensive overview of the state of the art in photogrammetric platforms and measurement techniques. A further lecture by Pirotti F. entitled Vegetation Related Applications of Laser and Spectral Remote Sensing offered insights into the RPAS sensor era and the sensor characteristics suitable for remote surveying of forests and areas of environmental interest in general (e.g. Pirotti, 2010; Pirotti et al., 2014). It illustrated the technological progress of sensors in terms of lower weight and costs, along with higher accuracy and efficiency in terms of battery duration. These advances allow companies to RPAS with laser and spectral sensors at affordable outlay. Forestry and vegetation studies often monitor study areas which are not easily accessible. Thus lighter equipment (e.g. TLS) and RPAS, which can be deployed quickly and with costs lower than, for instance, an airfare, are valuable alternative tools. The lecture also compared the utilization of photogrammetric techniques - i.e., SFM versus ALS over vegetation, and the full-waveform information that can be used along with certain laser sensors.

\subsection{Mapping mass movements and the cryosphere}

3.2.1 Terrestrial laser scanning: The group on deformation monitoring of mass movements used TLS to capture data of a landslide. Two periods were captured with heavy rainfalls inbetween. Figure 8 shows the area under investigation during data acquisition of the first period. The aim of this assignment was to analyse and apply the entire process chain of deformation monitoring on the given example, ranging from viewpoint planning, data acquisition and post processing to deformation measurement. After completion of data acquisition the focus was set on post-processing, testing and comparing different registration strategies, such as coarse registration, iterative closest point - ICP (CloudCompare), multi-station adjustment - MSA (RiscanPro) and cloud to cloud registration $\mathrm{C} 2 \mathrm{C}$ (Cyclone). Finally, registration results were evaluated according to their plausibility by separating registration errors from changes due to real landslide activity. As an outcome of this campaign, water-triggered erosion was detected and quantified in the centre of the landslide.

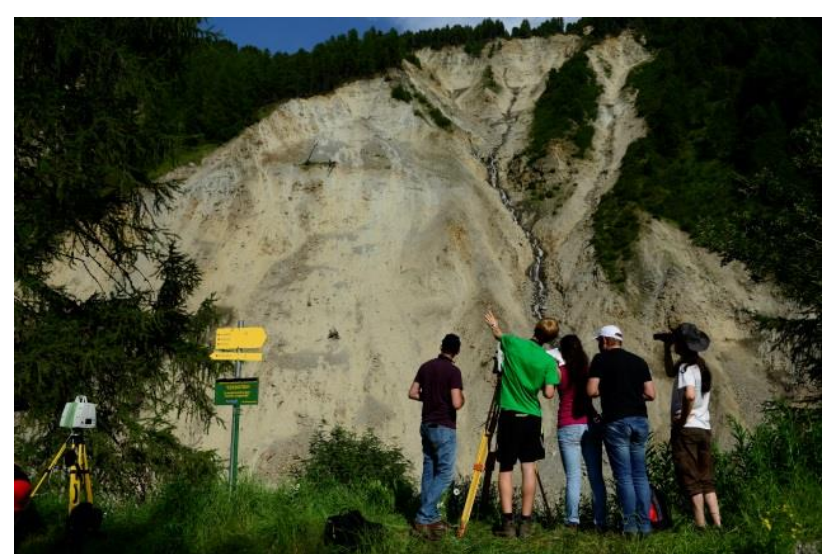

Figure 8. Data acquisition at the test site for mass movement monitoring 


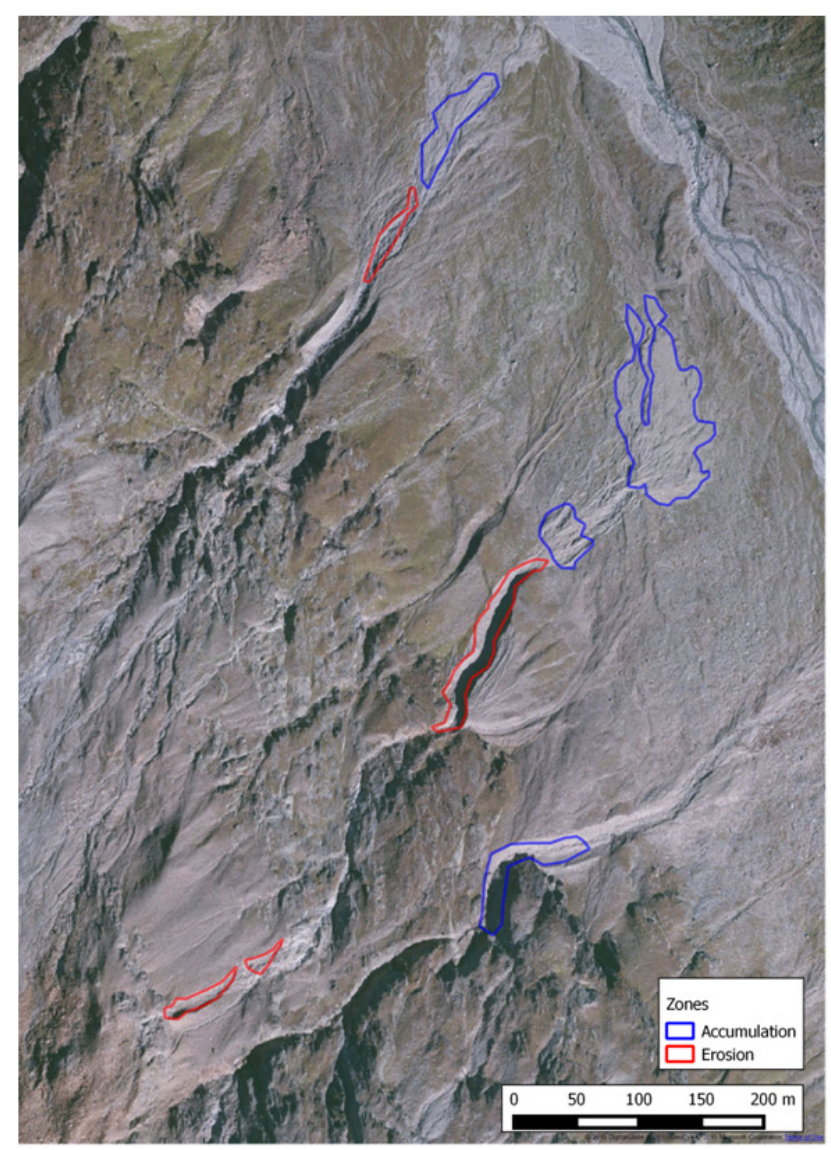

Figure 9. Erosion and accumulation areas in the proglacial zone of Hangerer Ferner

The group dealing with glaciology acquired TLS data in order to investigate the applicability for estimating glacier mass balance. TLS point clouds were acquired with a Riegl VZ-6000 very-long-range laser scanner. Scans were registered and georeferenced. Then change detection analysis was performed by comparing point clouds with ALS data from 2006. The group found a mean surface elevation change of $-3.6 \mathrm{~m}$ $( \pm 0.25 \mathrm{~m})$ and a total mass loss of 248 tons for Hangerer Ferner glacier, which corresponds to a water equivalent of $-3.04 \mathrm{~m}$. Furthermore, glacier surface classification by using signal intensity was investigated for distinguishing fresh snow from ice (Höfle \& Pfeifer, 2007; Höfle et al., 2007). In the proglacial zone, change detection of erosion and accumulation zones by different geomorphological processes could be identified (Höfle \& Rutzinger, 2001). Furthermore, the acquired TLS data, in combination with above mentioned ALS data, were used to quantify geomorphologic process results in the proglacial zone (see e.g. Sailer et al., 2014). The group was able to delineate distinct erosion and accumulation areas (Fig. 9) as well as to calculate the corresponding volume changes.

A second group's objective was mapping a rock glacier and comparing the acquired data with the ALS data set from 2011 to estimate surface changes. The group worked with a Riegl VZ400 and a Leica RTK GNSS GS15. Scanning set-up, basic registration and georeferencing workflows were tested at a rockfall area near the venue. From this data set surface feature calculations were derived, such as slope angle and roughness. On the fieldwork day TLS data from the Hochebenkar rock glacier were captured from several positions (see, e.g. Klug et al., 2014; Krainer et al., 2012). After georeferencing rock glacier change detection was applied (Fig. 10). A major challenge of close-range laser scanning of rock glaciers was the rough and difficult terrain in the debris area. Thanks to the high motivation and excellent fitness of the group members, a valuable dataset - the 2015 "anchor" - could be captured.

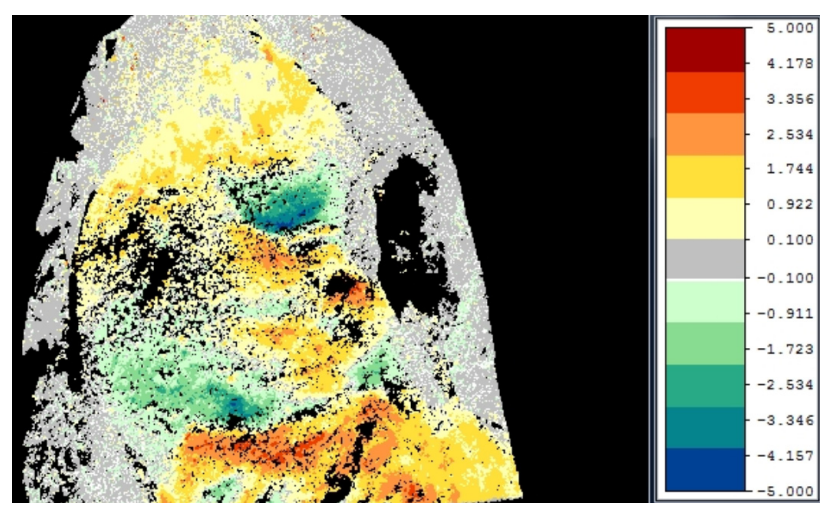

Figure 10. Change detection analysis comparing terrestrial (2015) and airborne laser scanning data (2011), indicating vertical elevation changes $[\mathrm{m}]$ due to rock glacier movement

3.2.2 Infrared thermography: The time series analysis of multi-temporal infrared thermal imagers is a valuable method for capturing thermal properties of natural surfaces (e.g. Berdoldi et al., 2010, Hopkinson et al., 2010). The objective of this group assignment was mapping thermal properties of a geomorphological structure such as the front of Hochebenkar rock glacier (Fig. 11).

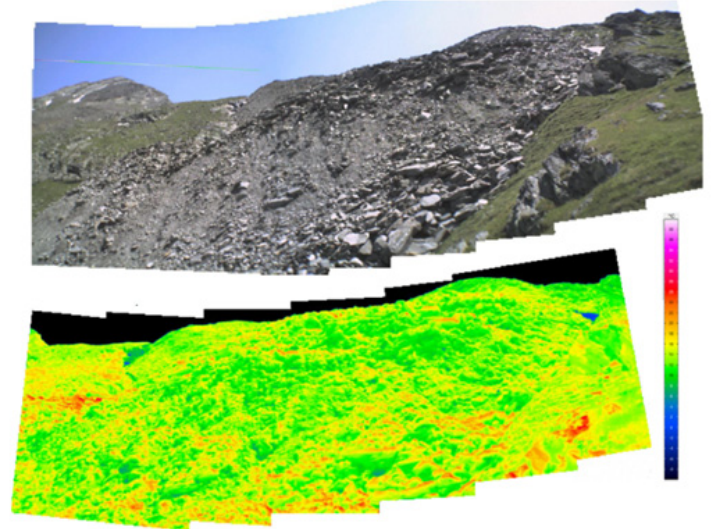

Figure 11: Stitched thermography panorama at Hochebenkar rock glacier.

The group worked with the VarioCam hr research (long-wave infrared 7.5-14.0 $\mu \mathrm{m}, 1280 \mathrm{x} 960$ resolution, F:30 mm, IFO 0.8 mrad, FOV $30 \times 23^{\circ}$, accuracy $1.5 \mathrm{~K}$, resolution $0.08 \mathrm{~K}$ at $30^{\circ} \mathrm{C}$ see, e.g., Zhang et al., 2015). First of all the measurement set-up was designed, consisting in the definition of an optimum measurement position. Radiation simulation tools helped to decide on the best measurement setting factors influencing the accuracy of thermographic measurements (e.g. emissivity of object surface, spectral transmission of the atmosphere, ambient temperature, etc.). Thermographic measurements were corrected and the reliability of temperature measurements was investigated, e.g. by simulating different settings of the boundary conditions. The group also analysed the opportunity for registering thermograms to the $3 \mathrm{D}$ geometry obtained from TLS (see Sect. 3.2.1 and Fig. 12). 


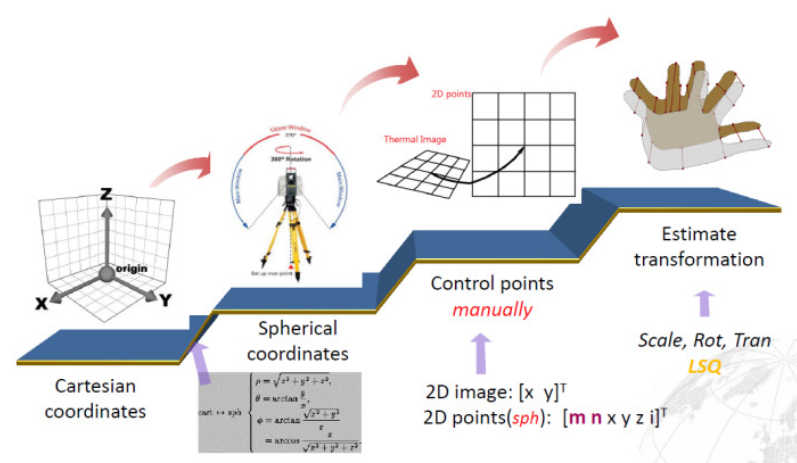

Figure 12. Workflow for registering infrared imagery to terrestrial laser scanning point clouds

3.2.3 Related geomorphologic and cryospheric lectures: The talk of Stötter, J. and Rutzinger, M. High mountain research in Ötztal - application of close-range sensing in high mountains introduced the participants to the 'research field lab' of the summer school, past research in the region and current activities making use of innovative close-range sensing techniques. The keynote of Tarolli, P. High definition topography for understanding Earth surface processes gave an overview of applications of close-range sensing and spatial analysis for investigating geomorphological processes (Tarolli 2014). Meißl G. and Höferl K. brought in background knowledge with their lecture on Natural Hazards - from assessment to decision making. The lecture of Wujanz, D. Registration of point clouds based on stable areas for deformation monitoring gave a deeper insight into registration of point clouds and potential error sources for monitoring tasks. Fundamentals of change detection were presented by Lindenbergh, R. in his lecture Detecting changes in point clouds (Lindenbergh and Pietrzyk, 2015). The lecture by Oude Elberink S. Object detection and classification by point cloud processing explained concepts of point cloud segmentation, classification and the concept of object-based analysis applied for natural objects. The keynote by Maas H.-G. Terrestrial photogrammetric techniques for glacier monitoring at high spatial and temporal resolution dealt with ice-flow monitoring using photogrammetric mapping approaches. The lecture by Sailer R. Mapping of the high mountain cryosphere gave a general introduction into key issues of glaciology and permafrost research, methods for mass balance calculations as well as close-range sensing and remote-sensing methods for monitoring the cryosphere.

\subsection{Bathymetry and braided river mapping}

3.3.1 Bathymetric LiDAR: LiDAR bathymetry is used for estimating hydraulic roughness, for analysing sedimentation and erosion processes like sediment volume change and the assessment of aquatic habitats. The group on laser scanner bathymetry worked with the Leica ScanStation C10, which has a wavelength of $532 \mathrm{~nm}$ (green LiDAR) and a resolution of $1 \mathrm{mrad}$ (horizontal and vertical). The bathymetric tests were conducted at a clear water pond, where scans from two positions were acquired. When laser rays hit the water surface, refraction occurs (e.g. Smith et al., 2012). Therefore the students had to correct the acquired point clouds for refraction. In addition they estimated the precision degradation depending on range and incidence angle, identified further error sources and finally separated points into three classes: water surface, lake bottom and surrounding terrain and vegetation (Fig. 13).

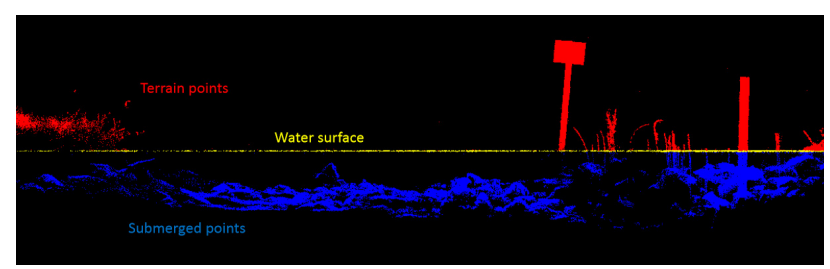

Figure 13. Classified bathymetric point cloud

3.3.2 Remotely piloted aircraft systems for braided river mapping: The objective of this group was to design an RPAS flight and process the data for orthophoto and digital surface model (DSM) generation. An area of $750 \times 250 \mathrm{~m}$ of an Alpine braided river was mapped in Rotmoos valley. Images were captured with $90 \%$ overlap and $3 \mathrm{~cm}$ ground resolution. A total data set of 350 images was captured at a time interval of $1.2 \mathrm{sec}$. The camera on board was a Sony NEX-5 (16 mm focal lens), see Figure 14.

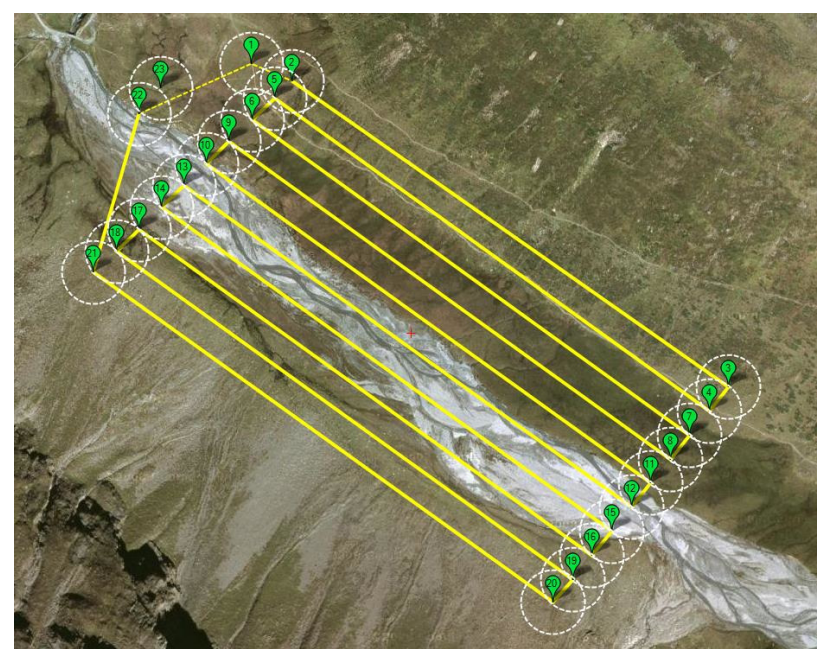

Figure 14. Plan of the remotely piloted aircraft system flight

The flight was conducted in very windy conditions by the Austrian Research Centre for Forests (BFW). Images were automatically oriented through a bundle adjustment including self-calibration to work out camera calibration parameters. The SFM approach implemented in Agisoft PhotoScan was used to extract tie points (Barazzetti et al., 2011). Some ground control points (GCPs) were positioned in the area covered by the RPAS flight. GCPs measurement was carried out using a theodolite and a GPS receiver operating in RTRK mode with respect to a master station temporarily located in Rotmoos valley, generating a DSM with $6 \mathrm{~cm}$ resolution. RMSE of $10 \mathrm{~cm}$ and $14 \mathrm{~cm}$ could be achieved. Such a DSM was obtained by applying the dense matching function implemented in Agisoft PhotoScan software.

3.3.3 Related lectures: The key note of Pfeifer, N. From sensors to point clouds gave insight into fundamentals of active close-range sensors focusing on point cloud processing, making use of reflectance strength and full-waveform laser scanning. The lecture of Scaioni, M. Georeferencing and registration of images and laser data gave insights into important principles of photogrammetry and laser scanning registration/geo-referencing techniques.

\section{LESSONS LEARNED}

In just one week of theory, practical lessons and in-the-field group work, early career scientist received deep insights in 
selected techniques of close-range sensing and their applications in environmental and geo-science. This was especially helpful for scientists from environmental and geosciences, such as geology, geography, ecology and climate change research, who gathered insights into close-range sensing techniques. Scientists from technical fields had the opportunity to broaden their knowledge into different applications of close-range sensing in related fields of mountain research. Such a set-up encouraged a common scientific language between disciplines and the emergence of common or complementary research questions. One challenge was how to address the different research levels of participants from early PhDs to PostDoc level. All in all. initiatives like the Innsbruck Summer School of Alpine Research 2015 are vital for stimulating interdisciplinary research activities and encouraging future collaboration across scientific disciplines.

\section{OUTLOOK}

The Innsbruck Summer School of Alpine Research 2015 was undoubtedly a great success and recognized as such by all participants. A quality assessment form was completed by the students who underlined positive points and made suggestions for further improvements. Ongoing activities are the hosting of an e-learning platform with all material generated during the summer school. Selected and extended material should be assembled in a hands-on textbook about close-range sensing in mountain research. Some participant groups continued working on their projects and have submitted the results for scientific publication. Given the overwhelmingly positive response of participants and the large number of requests for another event like this, we plan a follow-up summer school in 2017 with an updated and extended set of close-range sensors. More space will then be given to the complementary use of close-range sensors and remotely-sensed data from spaceborne sensors. Indeed, the application of satellite remote sensing has revealed a powerful tool for investigating the mountain environment and its processes (see, e.g., Kääb et al., 2006; Scaioni et al., 2014).

\section{ACKNOWLEDGEMENTS}

The organizing committee of the summer school wants to thank all supportive administrative staff from the University of Innsbruck and staff at the University Centre Obergurgl for the excellent support during the event. We also want to thank all sponsors of the summer school: the Faculty of Geo- and Atmospheric Sciences, the Vice Rector for Research, and the Alpine Research Centre Obergurgl of the University of Innsbruck, University of Padova, the Institute for Interdisciplinary Mountain Research of the Austrian Academy of Sciences, Laserdata GmbH, Leica Geosystems AG, Riegl Laser Measurement Systems GmbH and the Austrian Alpine Club. Our thanks also go to the Austrian Research Centre for Forests (Bundesforschungszentrum für Wald, BFW) for conducting the remotely piloted aircraft systems flight.

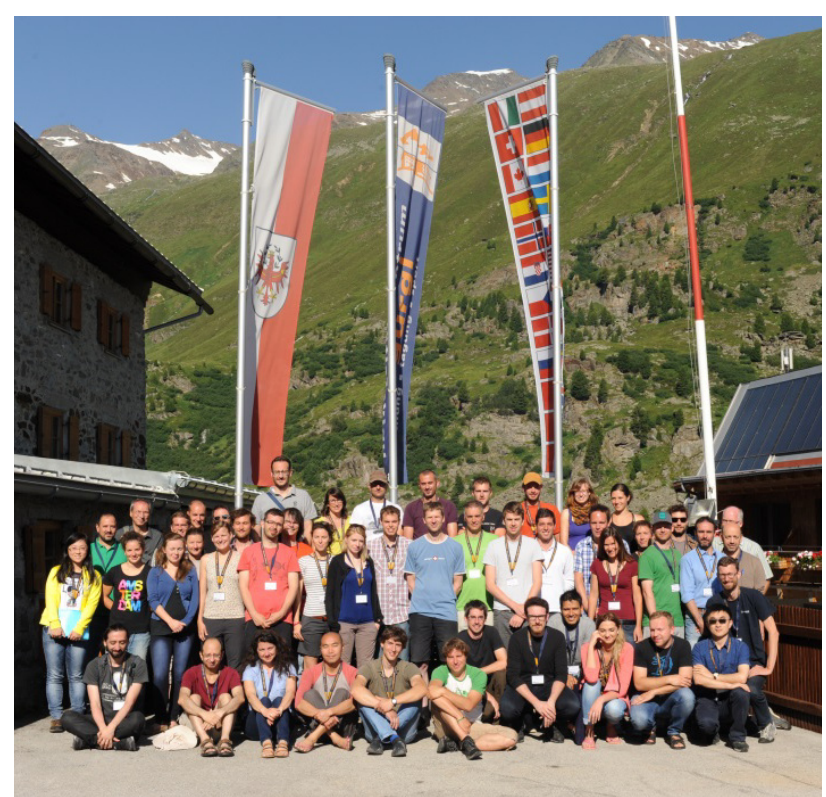

\section{REFERENCES}

Barazzetti L., Forlani G., Remondino, F., Roncella R., \& Scaioni M., 2011. Experiences and achievements in automated image sequence orientation for close-range photogrammetric projects. In: Proc. of SPIE - Int. Conf. Videometrics, Range Imaging, and Applications XI, Munich, Germany, Vol. 8085 (80850F), 13 pp. (e-doc), DOI: $10.1117 / 12.890116$

Bertoldi, G., Notarnicola, C., Leitinger, G., Endrizzi, S., Zebisch, M., Della Chiesa, S. \& Tappeiner, U., 2010. Topographical and ecohydrological controls on land surface temperature in an alpine catchment. Ecohydrology 3(2), pp. 189-204, DOI: 10.1002/eco.129.

Brodu, N., \& Lague, D., 2012. 3D terrestrial lidar data classification of complex natural scenes using a multi-scale dimensionality criterion: Applications in geomorphology. ISPRS Journal of Photogrammetry and Remote Sensing, 68, pp. 121-134, DOI:10.1016/j.isprsjprs.2012.01.006.

Höfle, B., \& Pfeifer, N., 2007. Correction of laser scanning intensity data: Data and model-driven approaches. ISPRS Journal of Photogrammetry and Remote Sensing, 62(6), pp. 415-433, DOI: 10.1016/j.isprsjprs.2007.05.008.

Höfle, B., \& Rutzinger, M., 2011. Topographic airborne LiDAR in geomorphology: A technological perspective. Zeitschrift für Geomorphologie, Supplementary Issues, 55(2), pp. 1-29, DOI: 10.1127/0372-8854/2011/0055S2-0043.

Höfle, B., Geist, T., Rutzinger, M., \& Pfeifer, N., 2007. Glacier surface segmentation using airborne laser scanning point cloud and intensity data. In: International Archives of Photogrammetry, Remote Sensing and Spatial Information Sciences, XXVI, Part 3, pp. 195-200.

Hopkinson, C., Bemth, B., M., Pomeroy, J., 2010. Mapping changing temperature patterns over a glacial moraine using oblique thermal imagery and lidar. Canadian Journal of Remote Sensing, 36(2), pp. 257-265, DOI: 10.5589/m10-053.

Kääb, A., Huggel, C., \& Fischer, L., 2006. Remote sensing technologies for monitoring climate change impacts on glacier- 
and permafrost-related hazards. In: Proceedings Geohazards, 11 pp.

Klug, C., Bollmann, E., Rieg, L., Sproß, M., Sailer, R. \& Stötter, J., 2014. Detecting and quantifying area wide permafrost change. In: permAfrost - Austrian Permafrost Research Initiative. IGF Forschungsberichte, 6. Verlag der Österreichischen Akademie der Wissenschaften, Wien, Austria, pp. 68-108.

Körner, C., 2012. Alpine Treelines - Functional Ecology of the Global High Elevation Tree Limits. Springer, Basel, 220 pp.

Krainer, K., Kellerer-Pirklbauer, A., Kaufmann, V., Lieb, G., K., Schrott, L. \& Hausmann, H., 2012. Permafrost research in Austria: History and recent advances. Austrian Journal of Earth Sciences 1052(2), pp. 2-11.

Kukko, A., Kaartinen, H., Hyyppä, J., \& Chen, Y., 2012. Multiplatform mobile laser scanning: Usability and performance. Sensors, 12(9), pp. 11712-11733, DOI: 10.3390/s120911712.

Lindenbergh, R. \& Pietrzyk, P., 2015. Change detection and deformation analysis using static and mobile laser scanning. Applied Geomatics, 7(2), pp. 65-74, DOI: 10.1007/s12518-0140151-y.

Luhmann, T., Robson, S., Kyle, S., \& Boehm, J., 2013. Close Range Photogrammetry: 3D Imaging Techniques. Walter De Gruyter Inc., Germany, 702 pp.

Oude Elberink, S.J. \& Kemboi, B.J., 2014. User-assisted object detection by segment based similarity measures in mobile laser scanner data. In: International Archives of Photogrammetry, Remote Sensing and Spatial Information Sciences, XL-3. pp. 239-246.

Pirotti, F., 2010. Assessing a template matching approach for tree height and position extraction from lidar-derived canopy height models of Pinus pinaster stands. Forests, 1(4), pp. 194208, DOI: $10.3390 /$ f1040194.

Pirotti, F., Laurin, G., Vettore, A., Masiero, A., \& Valentini, R., 2014. Small footprint full-waveform metrics contribution to the prediction of biomass in tropical forests. Remote Sensing, 6(10), pp. 9576-9599, DOI: 10.3390/rs6109576.

Remondino, F., Del Pizzo, S., Kersten, T. P., \& Troisi, S., 2012. Low-cost and open-source solutions for automated image orientation - A critical overview. In: Progress in Cultural Heritage Preservation. Springer Berlin Heidelberg, Germany. pp. 40-54.

Remondino, F., Spera, M.G., Nocerino, E., Menna, F., \& Nez, F., 2014. State of the art in high density image matching. Photogrammetric Record, 29(146), pp. 144-166, DOI: 10.1111/phor.12063.

Rothermel, M., Wenzel, K., Fritsch, D. \& Haala, N., 2012. SURE: Photogrammetric Surface Reconstruction from Imagery. In: Proc. LC3D Workshop, Berlin, Germany, pp. 1-9.

Sailer, R., Rutzinger, M., Rieg, L., \& Wichmann, V., 2014. Digital elevation models derived from airborne laser scanning point clouds: appropriate spatial resolutions for multi-temporal characterization and quantification of geomorphological processes. Earth Surface Processes and Landforms, 39(2), pp. 272-284, DOI: 10.1002/esp.3490.
Scaioni, M., Longoni, L., Melillo, V., Papini, M., 2014. Remote Sensing for Landslide Investigations: An Overview of Recent Achievements and Perspectives. Remote Sensing, 6(10), pp. 9600-9652, DOI: 10.3390/rs6109600.

Smith, M., Vericat, D. and Gibbins, C., 2012. Through-water terrestrial lasers scanning of gravel beds at the patch scale. Earth Surface Processes and Landforms, 37(4), pp. 411-421, DOI: 10.1002/esp.2254.

Tarolli, P., 2014. High-resolution topography for understanding Earth surface processes: opportunities and challenges. Geomorphology, 216, pp. 295-312, DOI: 10.1016/j.geomorph.2014.03.008.

Zhang, Y., Chen, Y. \& Luo, C., 2015. A method for improving temperature measurement precision on the uncooled infrared thermal imager. Measurement 74, pp. 64-69, DOI: 10.1016/j.measurement.2015.07.016. 